\title{
An Ergonomic Assessment of Upper Limb Musculoskeletal Risk Factors Using Revised Strain Index and Threshold Limit Value for Hand Activity Level in Hand-swen Shoe Workers
}

\author{
Mohammad Aghazadeh $^{1}$, Abolfazl Ghahramani², Mohammad Hajaghazadeh ${ }^{2}$,* \\ ${ }^{1}$ MS Student of Ergonomics, Faculty of Health, Urmia University of Medical Sciences, Urmia, Iran \\ ${ }^{2}$ Assistant Professor, Department of Occupational Health, Faculty of Health, Urmia University of Medical Sciences, Urmia, \\ Iran \\ * Corresponding Author: Mohammad Hajaghazadeh, Department of Occupational Health, Faculty of Health, Urmia University
} of Medical Sciences, Urmia, Iran. Email: hajaghazadeh@gmail.com

Received: $21 / 12 / 2017$

Accepted: 07/03/2018

How to Cite this Article:

Aghazadeh M, Ghahramani A. Hajaghazadeh M. An Ergonomic Assessment of Upper Limb Musculoskeletal Risk Factors Using Revised Strain Index and Threshold Limit Value for Hand Activity Level in Hand-swen Shoe Workers. J Occup Hyg Eng. 2018; 4(4): 39-46. DOI: ---

\begin{abstract}
Background and Objective: Repetitive movements and overexertion during occupational activities can lead to musculoskeletal disorders in the upper limbs. Regarding this, the aim of the present study was to assess the ergonomic risk factors of the upper limb extremities using modified Revised Strain Index (RSI) and threshold limit value for hand activity level (TLVHAL) methods in hand-swen shoe workers in Tabriz, Iran.

Materials and Methods: This cross-sectional sudy was conducted on 218 hand-swen shoe workers to assess their stergonomic exposure using the RSI and TLV-HAL methods. The assesment of the study variables was acomplished through direct observation and videotaping of the work-cycles. The data were analyzed by descriptive and analytical methods, such as oneway ANOVA, Spearman correlation, and Kappa statistics.

Results: In this study, 218 workers were recruited working in three tasks of preparation $(n=69)$, sewing $(n=63)$, and shoemaking $(n=86)$. The mean scores of RSI for sewing, preparation, and shoemaking workers were 9.30, 46.10 , and 95.90, respectively. Furthemore, the mean scores of TLV-HAL for these tasks were $0.27,0.81$, and 1.70 , respectively. Almost all workers in preparation and shoemaking tasks were categorized in the group with hazardous level of exposure, while the sewing workers were classified in the group of safe exposure level. The TLV-HAL scores were significantly correlated with the RSI scores.

Conclusion: According to the results, the workers in preparation and shoemaking tasks were at a higher risk of upper limbs musculoskeletal disorders due to repetitive actions and overexertion. Therefore, ergonomic interventions are suggested for these tasks to reduce the level of these risk factors.
\end{abstract}

Keywords: Ergonomic Assessment; Overexertion; Repetitive Action; Shoemaking 
do:

مقاله يزوهشى

\title{
ارزيابى اركونوميكى عوامل خطر اندامهاى فوقانى با استفاده از روشهاى شاخص تنش اصلاحشده (RSI) و حد آستانه مجاز سطح فعاليت دست (TLV-HAL) در كاركران سازنده كفش دست الموز
}

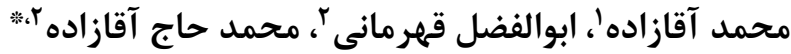

' ل دانشجوى كارشناسى ارشد اركَونومى، دانشكده بهداشت، دانشكاه علوم يزشكى اروميه، اروميه، ايران

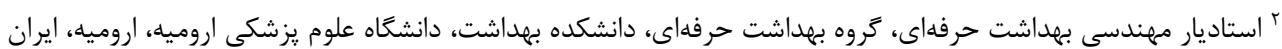

* نويسنده مسئول: محمد حاج آقازاده، كروه بهداشت حرفهاى، دانشكده بهداشت، دانشكاه علوم يزشكى اروميه، اروميه، ايران.

ايميل: hajaghazadeh@gmail.com

جكيده

سابقه و هدف: حر كات تكرارى و اعمال نيروى زياد در فعاليتهاى شغلى مى تواند منجر به بروز اختلالات

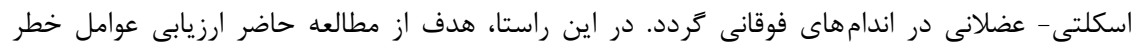

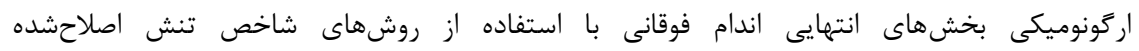

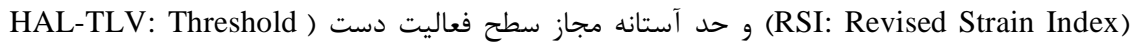

(Limit Value for Hand Activity Level

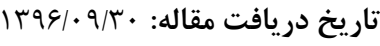

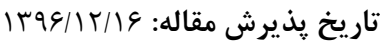

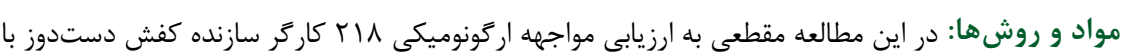

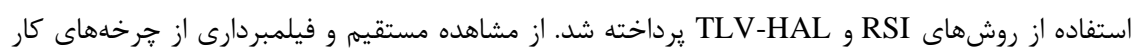

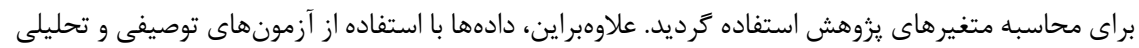

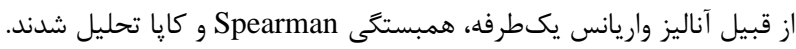

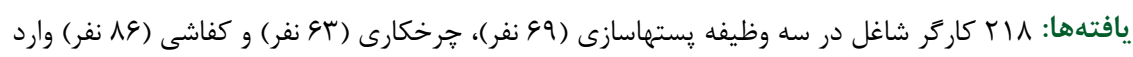

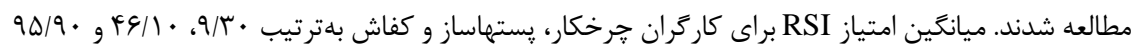

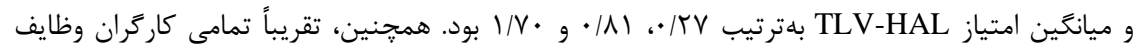

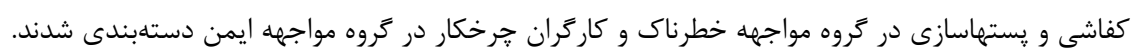

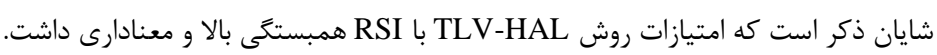

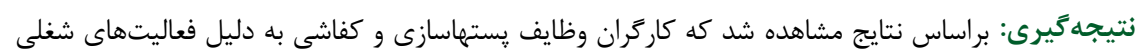

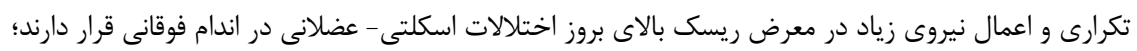

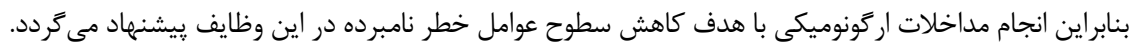
يزشكى همدان محفوظ است.

يوسجر كارى نامناسب، فشارهاى تماسى و ارتعاش از مههمترين

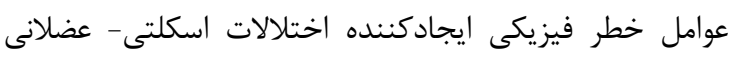
مىباشند [ه]]. اختلالات اسكلتى - عضلانى اندامهاى فوقانى بادئ

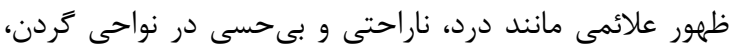

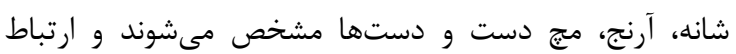

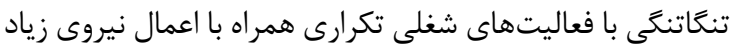

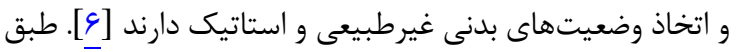

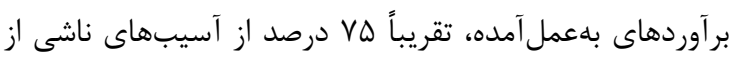

اختلالات اسكلتى - عضلانى عامل اصلى ازدسترفتن زمان

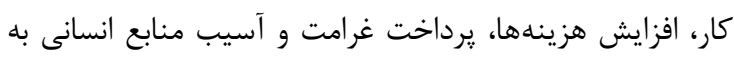

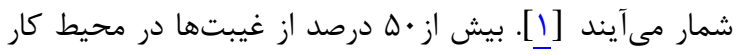

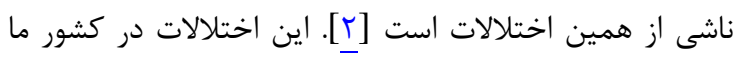

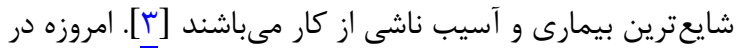

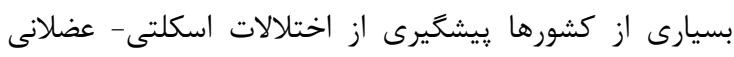

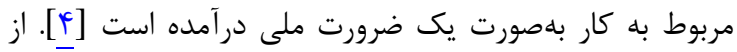

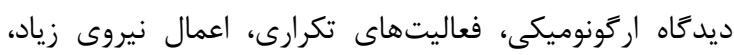


بنابراين براساس مطالعات قبلى، روشهاى SI و TLV-HAL

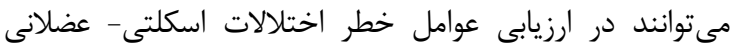

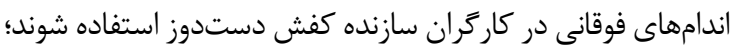

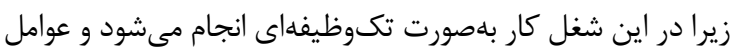

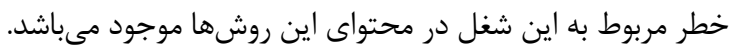

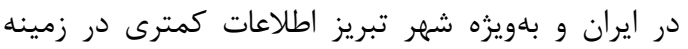

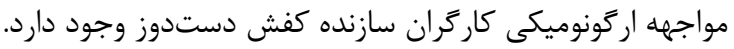

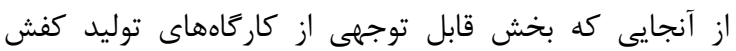

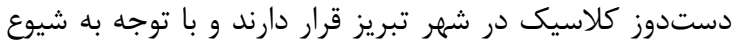
بالاى اختلالات اسكلتى - عضلانى اندام فوقانى در كاركران مشان مشابه

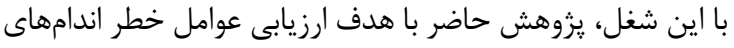

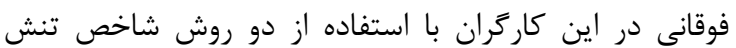

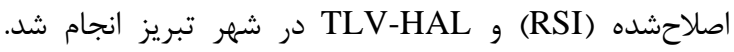
علاوهبراين بهعنوان هدف فرعى، ميزان همبستگى و توافق نتايج

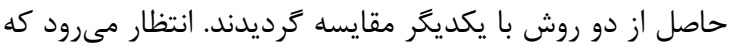

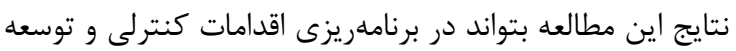

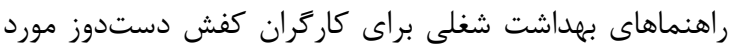

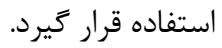

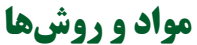

اين مطالعه مقطعى كه از نوع توصيفى- تحليلى بود با كإنا

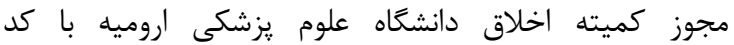

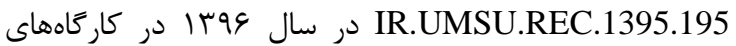
كوجى توليد كفش دستدوز در شهر تبريز انجام شد. پِيش از

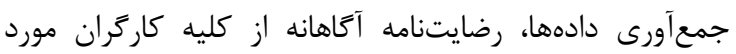
مطالعه اخذ كرديد. تعداد كاركران مورد مطالعه

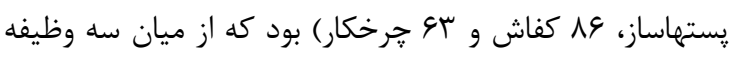

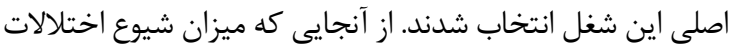

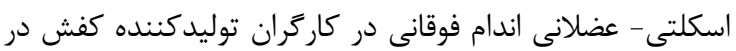
ايران كزارش نشده است، از يك مطالعه مشابه خارجى كه در دران

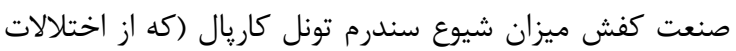

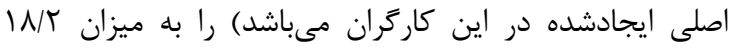

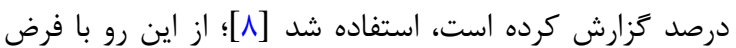
(P=.//AT)

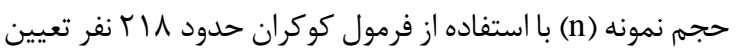

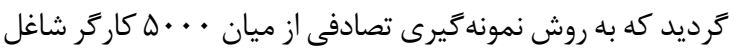

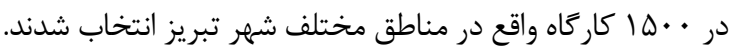

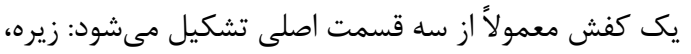

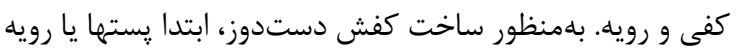

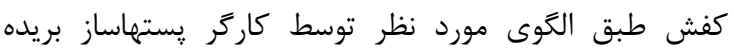

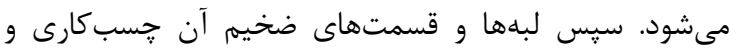

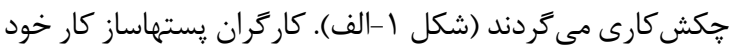

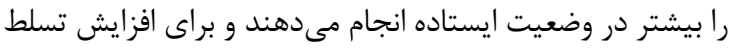
خود ساعتهاى طولانى با كردن خميده و در در حالت ايستاده
وظايف تكرارى مربوط به اندامهاى فوقانى مىباشند [V] صنعت كفش يكى از صنايع عمده توليدى است. شهر تبريز با توليد بخش قابل توجهى از اين محصول بهعنوان قطب توليد

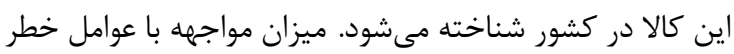

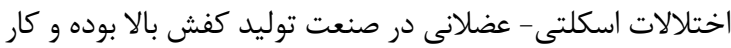

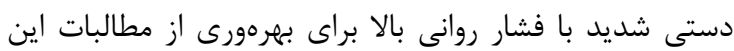

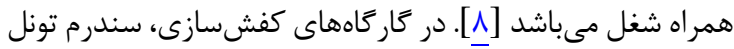

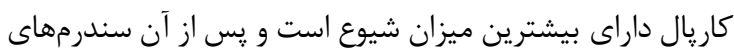
روتاتور كاف، تنش كردن و تونل كوبيتال بهترتيب در ردهدهاى

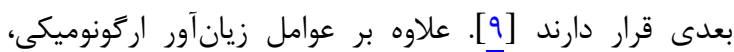

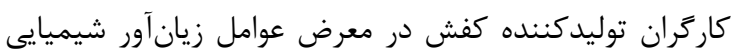

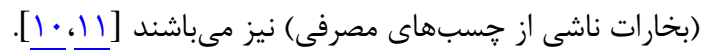

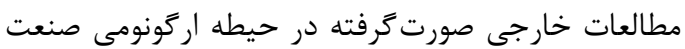

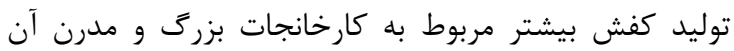

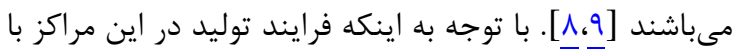

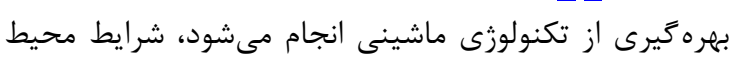

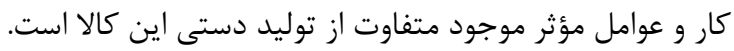

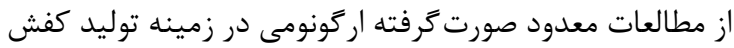

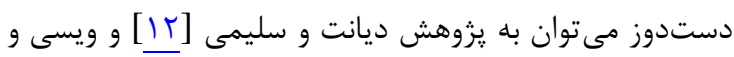

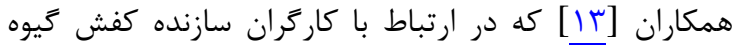

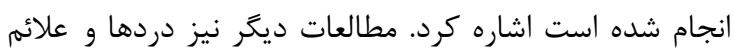

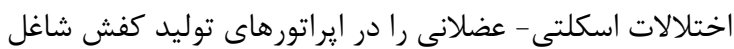

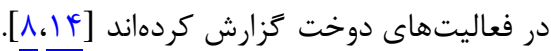
روشهاى مختلفى از قبيل شاخص تنش (SI)، حد آستانه

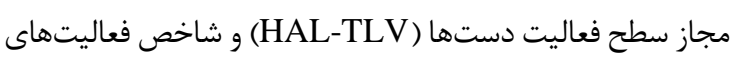
OCRA: Occupational Repetitive) شغلى تكراري - اختصاصاً براى ارزيابى عوامل خطر اختلالات اسكلتى (Actions عضلانى در اندامهاى فوقانى مشاغل تكوظيفهاى توسعه داده

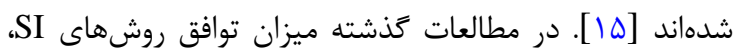

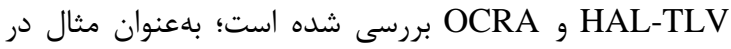

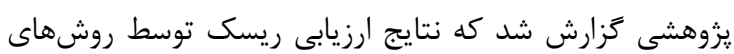

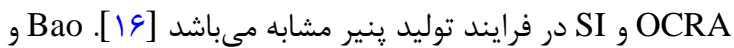
همكاران نيز توافق روش SI و SLV-HAL را متوسط تا قابل

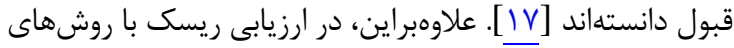

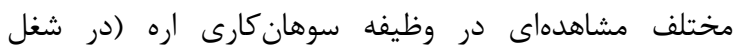

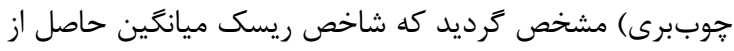
دو روش OCRA و SI با افزايش آسيبهاى اسكلتى- عضلانى

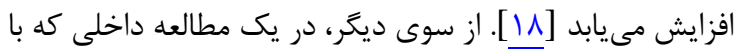

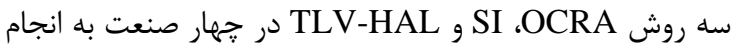
رسيد، مشخص ترديد كه بين روشهاى OCRA و SI و نيز SI و TLV-HAL كه روشهاى SAL-TLV و SI نسبت به روش OCRA از

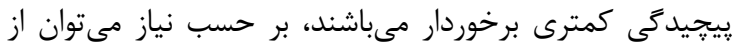

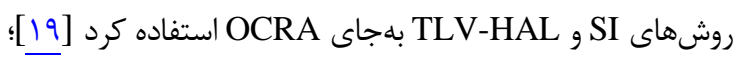


جسب كارى و ميخ كوبى كفى به زير قالب كفش مىباشد انجام

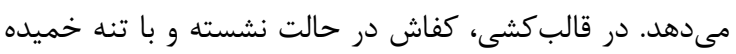

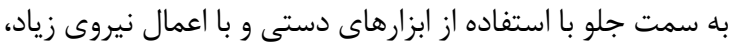

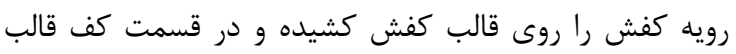

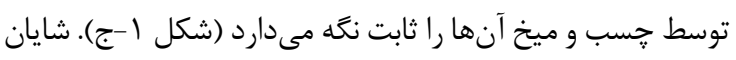

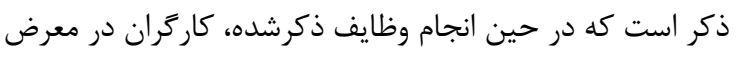

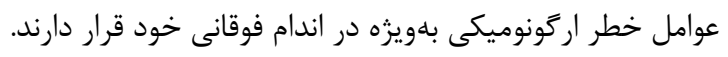

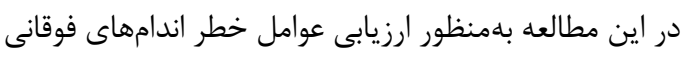

مشغول جكشزدنهاى مكرر مىباشند. يس از اين مرحله، كاركر

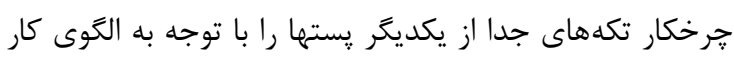

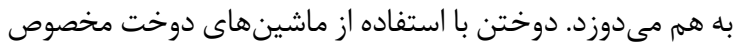

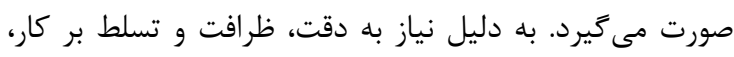

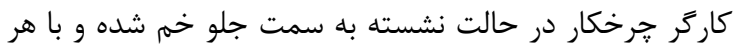

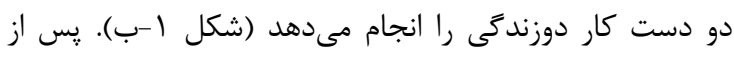

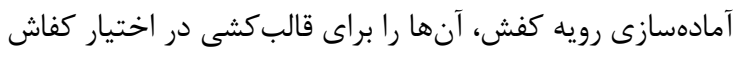
قرار مى دهند. كفاش قبل از قالب كشى مقدمات كار رأ را كه شامل

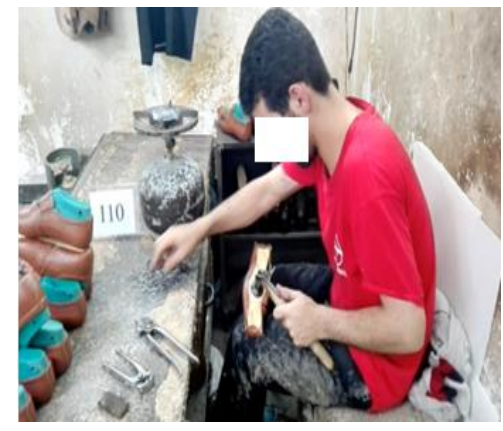

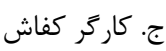

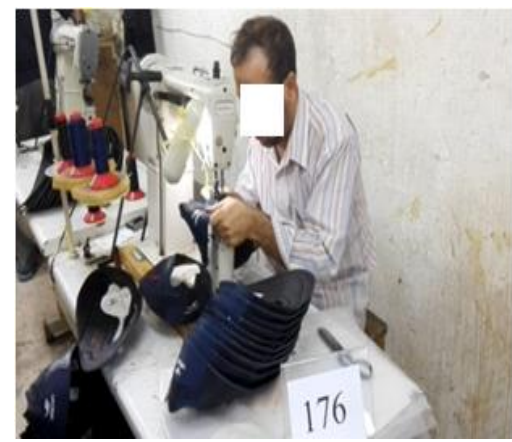

ب. بارگر خرخكار

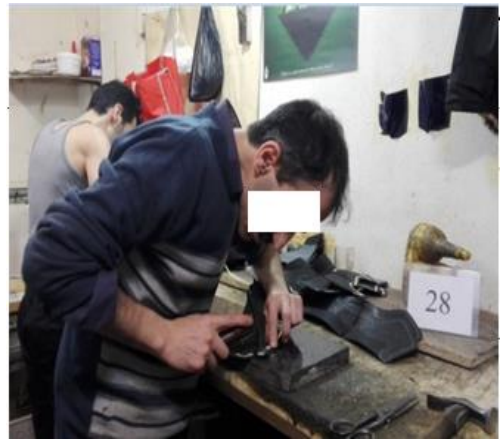

الف. كارگ يستهاساز

شكل ا: تصاوير كاركران حين انجام وظايف يُتهاسازى (الف)، جرخكارى (ب) و كفاشى (ج)

مدت زمان انجام وظيفه در روز (H): كل زمان صرفشده در روز

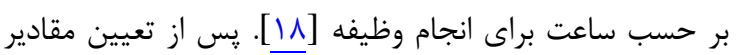
متغيرهاى ينج

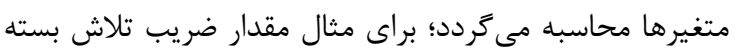

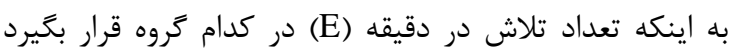
توسط فرمول زير محاسبه مىشود:

$E M=\left\{\begin{array}{l}0.10+0.25 . E, E \leq 90 / m \\ 0.00334 . E^{1.96}, E>90 / m\end{array}\right.$

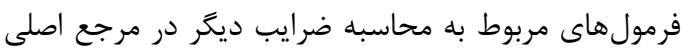

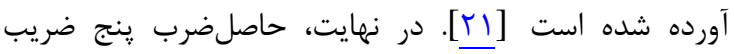
محاسبهشده توسط فرمول زير منجر به محاسبه مقدار

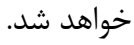

$\mathrm{RSI}=\mathrm{IM} \times \mathrm{EM} \times \mathrm{DM} \times \mathrm{PM} \times \mathrm{HM}$

Intensity of (Force) Multiplier) IM در معادله فوق Exertions per Minute ) EM ضريب شدت، (Exertion Duration ) DM ضريب تلاش، (frequency) Multiplier

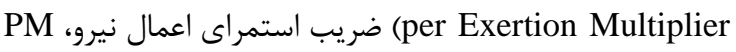
ضريب يوسجر و Hand/wrist Posture Multiplier) ضريب مدت (Duration of Task per Day Multiplier) زمان وظيفه مىباشد. براساس مقدار RSI بهدستآمده مىتوان

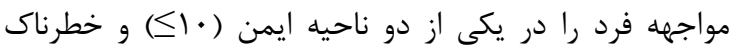
(1)
در كارگران سازنده كفش دستدوز از دو روش ارزيابى مشاهدهاى

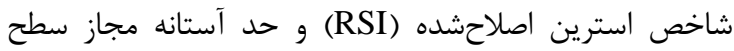

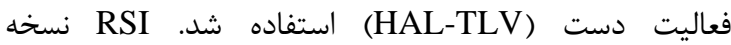
اصلاحشده روش شاخص تنش (SI) مىباشد كه در سال لهون توسط Moor و Garg براى ارزيابى فيزيكى اندامهاى فوقانى ارائه

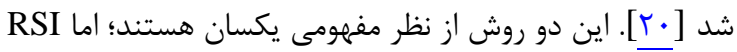

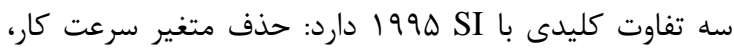
توجه به مدت زمان هر اعمال نيرو بهجاى سيكل وظيفه و استفاده

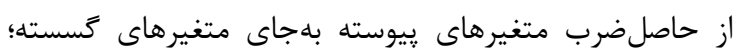

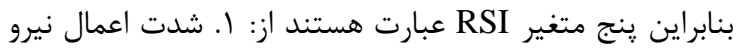

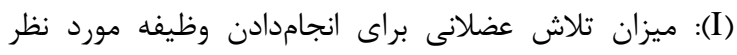

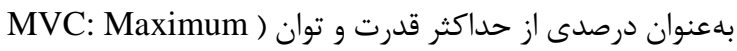
(Voluntary Contraction نيروى دركشده بورى (Borg CR-10) بهصورت كيفى محاسبه

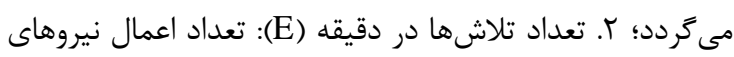

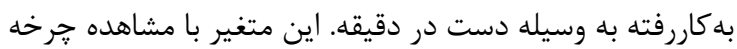

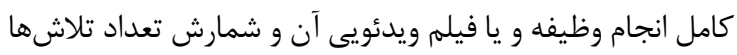

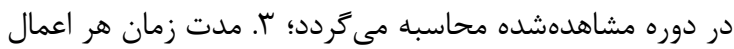

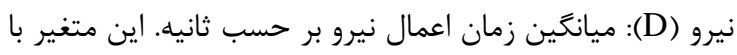

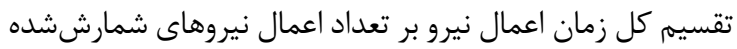

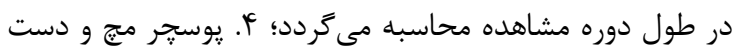

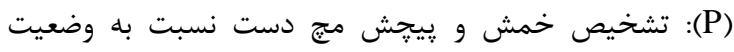

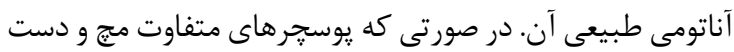

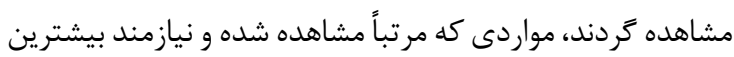

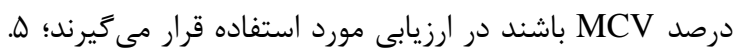


دادههايى از قبيل مواجهه هاى فيزيكى، تاريخجه يزشكى، عوامل

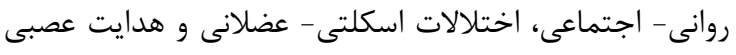

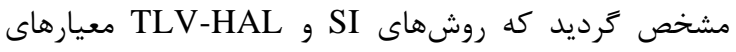
سودمندى جهت تخمين مواجهه با استرسورهاى بيومكانيكى

مىباشند [Yl]

بهنظور آناليز آمارى دادهها از نرمافزار 16 SPSS استفادهاد شد. همجنين آزمونهاى توصيفى جهت آمارى محاسبه مقادير شاخصهاى RSI و HAL-TLV به كار رفت و از آزمون تحليلى آنسي آناليز واريانس يكىطرفه براى مقايسه ميانكين نمره اين شاخصها

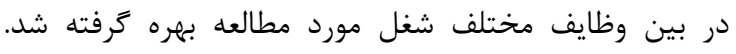

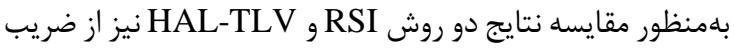
توافق كايا و ضريب همبستگى Spearman استفاده كرديد.

\section{افافته ه.}

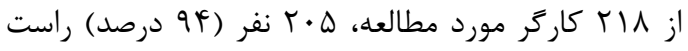

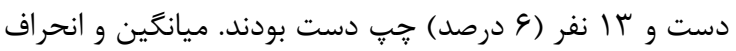

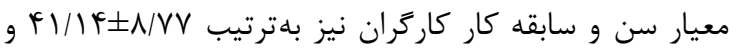

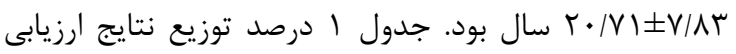

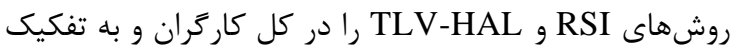

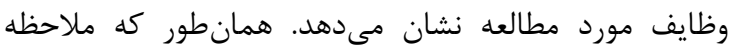

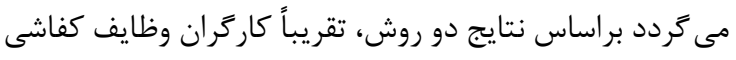

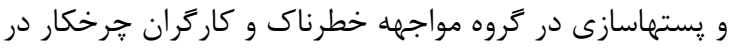
كروه مواجهه ايمن قرار دارند.

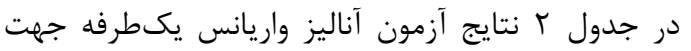
بررسى اختلاف ميانگين امتياز RSI در بين سه وظيفه أنون مورد

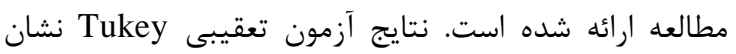

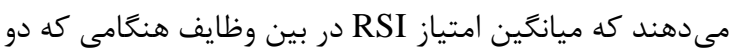

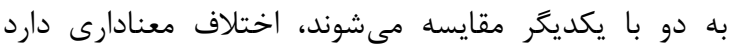

. $(\mathrm{P}=\cdot / \cdot \cdot 1)$
روش حد آستانه مجاز سطح فعاليت دست توسط انجمن

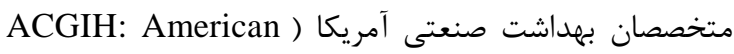
Conference of Governmental Industrial عوامل خطر شغلى منجر به اختلالات اسكلتى- عضلانى اندامهاى فوقانى در مشاغل تكوظيفهاى كه حداقل براى جهار

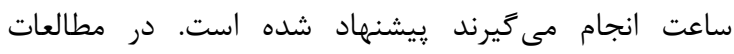

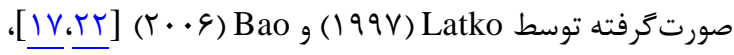
روايى و پايايى اين روش متوسط ارزيابى شده است. اين روش نوسط

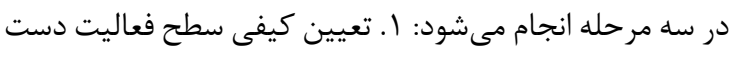
بر روى يك مقياس صفر (HAL: Hand Activity Level)

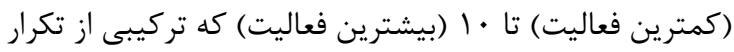

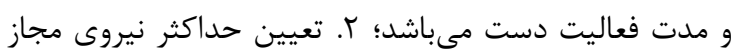

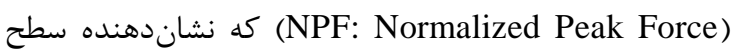
تلاش براساس اعمال نيروى زياد در يك جرخه كارى است.

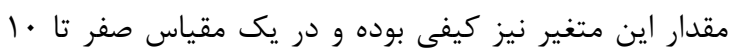

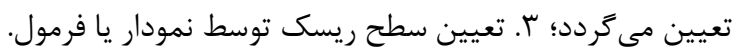

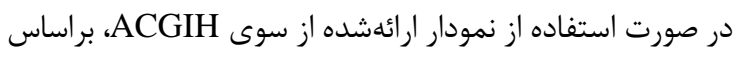

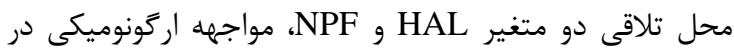

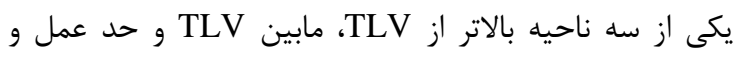

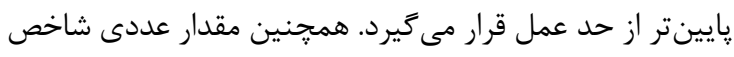
مA HAL كردد. در اين صورت مقدار شاخص مىتواند در يكى از گروههاى

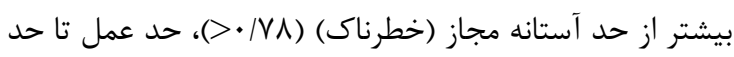

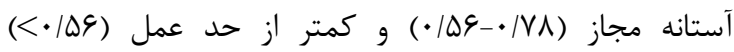
دستهبندى شود [rr] روش هاى SI و TLV-HAL در جندين مطالعه كوهورت

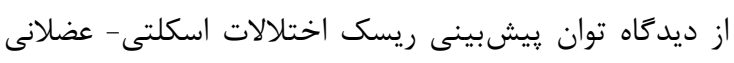

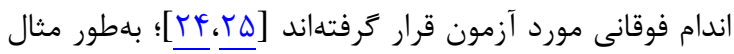
در يك مطالعه كوهورت با طول مدت شش سال و ثبت ماهانه

جدول ا: درصد توزيع نتايج ارزيابى روشهاى RSI و TLV-HAL در وظايف ساخت كفش دستدوز

\begin{tabular}{|c|c|c|c|c|c|}
\hline \multicolumn{3}{|c|}{ HAL-TLV } & \multicolumn{2}{|c|}{ RSI } & \multirow[b]{2}{*}{ وظايف كارى } \\
\hline $\begin{array}{c}\text { مواجهه خطرناى } \\
(>/ V \wedge)\end{array}$ & مواجهه حد عمل & 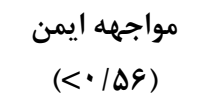 & 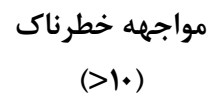 & 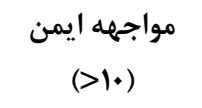 & \\
\hline $9 \Delta(ص د, 9 F / r)$ & $r($ r & | (أ درصد) & 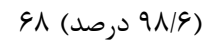 & | (أدرصد) & يستهاسازى \\
\hline 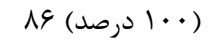 & (• درصد) · & (· (درصد) · & م & (• درصد) · & كفاشى \\
\hline$\Delta($ Dر V/q) & (· درصد) · & $\Delta \Lambda(ص د, 9 r / 1)$ & (· درصد) · & (• ( درصد) س & ترخكارى \\
\hline 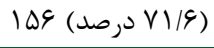 & $r(1 / \uparrow)$ & $\Delta q($ ( $\Delta, r V / I)$ & $1 \Delta F(\Delta, \nabla \cdot \mid q)$ & 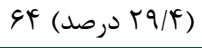 & كل كارگران \\
\hline
\end{tabular}

جدول r: مقايسه ميانگين امتياز روش RSI در بين سه وظيفه مورد مطالعه

\begin{tabular}{|c|c|c|c|c|c|c|}
\hline \multicolumn{2}{|c|}{ نتيجه آزمون } & \multirow{2}{*}{ حداكثر } & \multirow{2}{*}{ حداقل } & \multirow{2}{*}{ انحراف معيار } & \multirow{2}{*}{ ميانغين } & \multirow{2}{*}{ وظايف كارى } \\
\hline $\mathbf{F}$ & معنادارى & & & & & \\
\hline \multirow{3}{*}{$G \mid Y / T F$} & \multirow{3}{*}{$\cdot 1 \cdot \cdot 1$} & $1 \cdot \Delta / \varphi$. & $1 / 91$ & $|f / 9|$ & $\mid \varepsilon / 1$. & يستهاسازى \\
\hline & & $\mid \Delta T / T \Lambda$ & $r \cdot / f F$ & $r \cdot / \cdot \Delta$ & $৭ \Delta / ৭$. & كفاشى \\
\hline & & १/^६ & $\Lambda / 1 \Lambda$ & $\cdot / 4$. & $9 / \%$. & جرخكارى \\
\hline
\end{tabular}


روش SI سطوح ريسك از سه سطح به دو سطح كاهش يافته

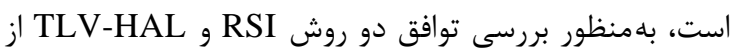

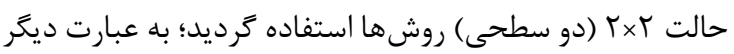

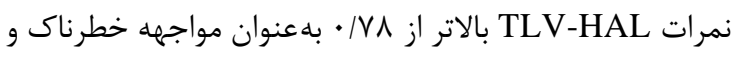

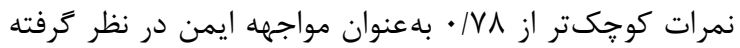

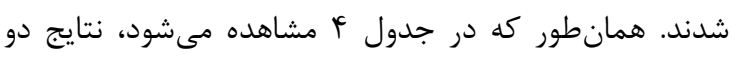

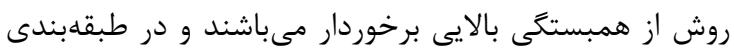

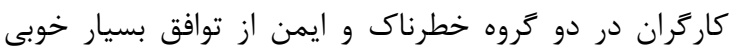
برخوردار هستند. - ان.
در جدول r نتايج آزمون آناليز واريانس يكطرفه براى

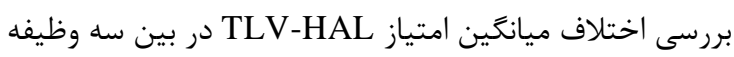

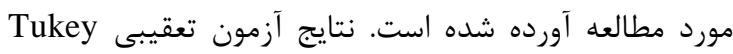

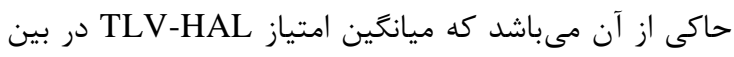

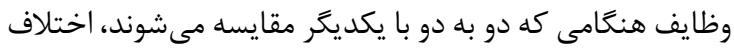

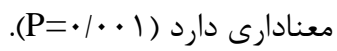

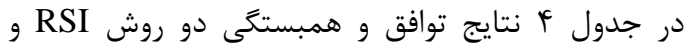

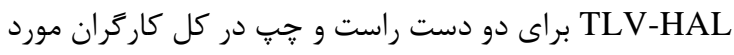

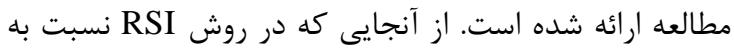

جدول بّ: مقايسه ميانگين امتياز روش TLV-HAL در بين سه وظيفه مورد مطالعه

\begin{tabular}{|c|c|c|c|c|c|c|}
\hline \multicolumn{2}{|c|}{ نتيجه آزمون } & \multirow{2}{*}{ حداكثر } & \multirow{2}{*}{ حداقل } & \multirow{2}{*}{ انحراف معيار } & \multirow{2}{*}{ ميانكَين } & \multirow{2}{*}{ وظايف كارى } \\
\hline $\mathbf{F}$ & معنادارى & & & & & \\
\hline \multirow{3}{*}{$.1 \cdot .1$} & \multirow{3}{*}{ س } & . & .111 & $.1 \cdot 9$ & $\cdot|\lambda|$ & پِتههاسازى \\
\hline & & $1 / V \Delta$ & • & $\cdot / T r$ & $1 / V$ & كفاشى \\
\hline & & . & . /Tr & .119 & $\cdot / T V$ & קرخكارى \\
\hline
\end{tabular}

جدول F: مقايسه ميزان توافق و همبستگى دو روش RSI و TLV-HAL براى دو دست راست و جֶٍ

\begin{tabular}{|c|c|c|c|c|}
\hline \multicolumn{2}{|c|}{ همبستخى } & \multicolumn{2}{|c|}{ 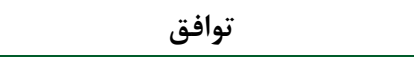 } & \multirow{2}{*}{ 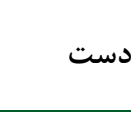 } \\
\hline 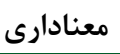 & ضريب همبستگى Spearman & معنادارى & ضريب كايا & \\
\hline$\cdot 1 \cdot \cdot 1$ &.$/ 91$ & $\cdot 1 \cdot \cdot 1$ &.$/ 91$ & دست راست \\
\hline$\cdot 1 \cdot \cdot 1$ & $\cdot 1 \wedge 9$ & $\cdot 1 \cdot \cdot 1$ &.$/ 94$ & دست جֶ \\
\hline
\end{tabular}

كارگر شاغل در أl شركت توليد كفش برزيلى انجام دادند و

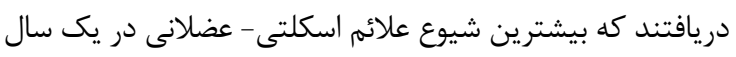

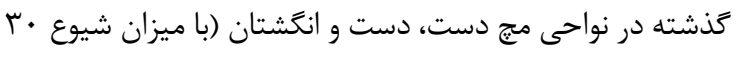

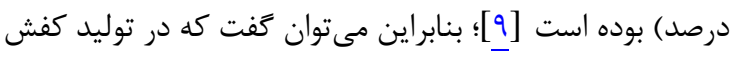

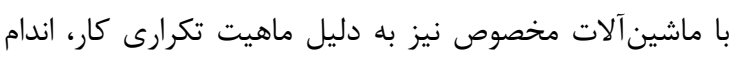

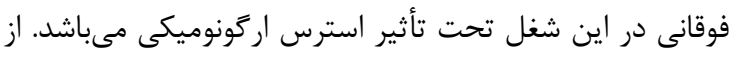

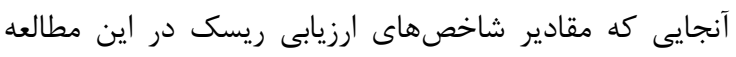

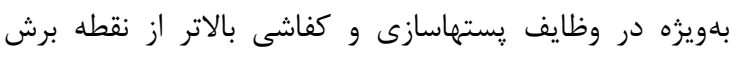
مواجهه خطرناك بود، مىتوان گفت كه بيشتر كاركران مورد

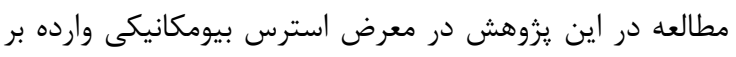
اندام فوقانى قرار داشتند.

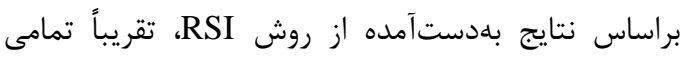

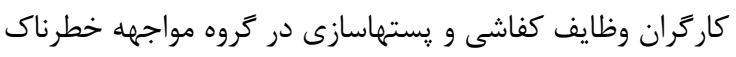

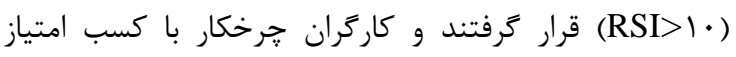

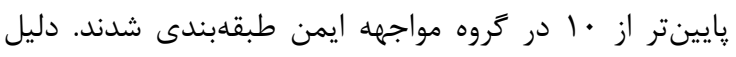

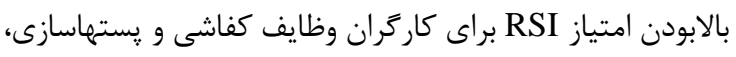

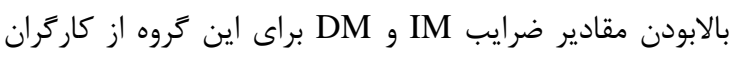

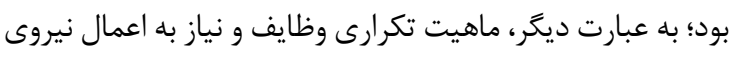
بيشتر حين انجام اين وظايف منجر به افزايش سطح رئن ريسك

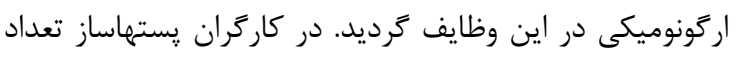

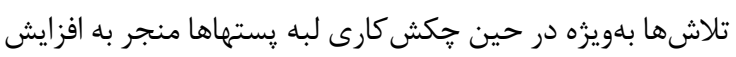

هدف از يزوهش حاضر، ارزيابى ريسك ارگونوميكى عوامل

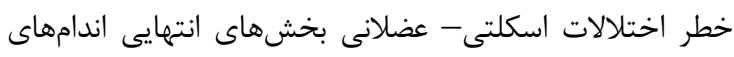

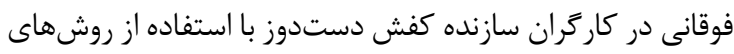

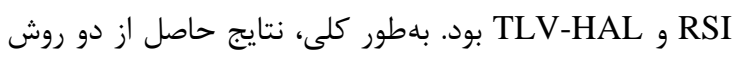
TLV-HAL و RSI

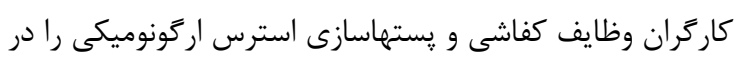

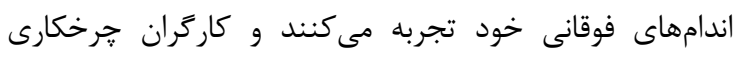
مواجها اركونوميكى ايمنى دارند.

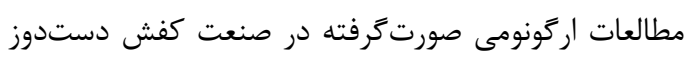

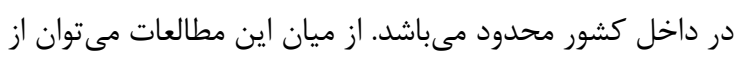

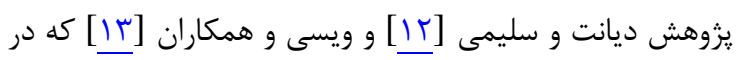

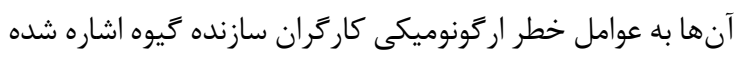

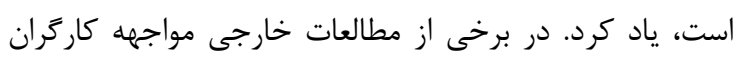

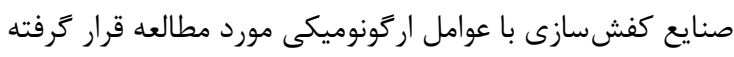

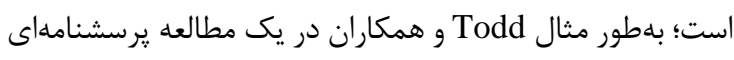

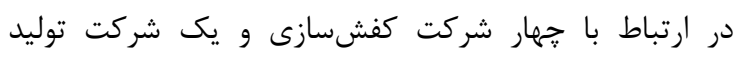

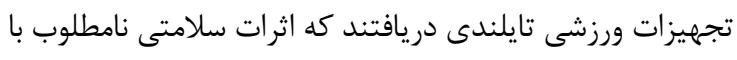

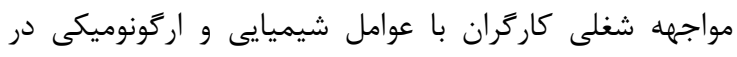

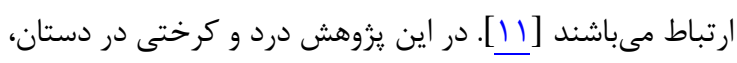

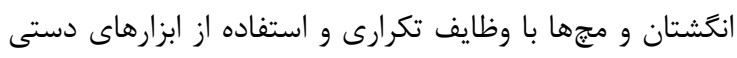

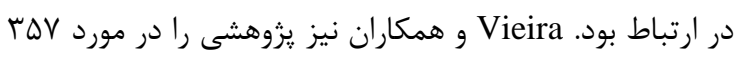




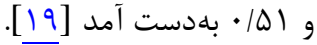
علاوه بر عوامل فيزيكى كار، عوامل روانى- اجتماعى نيز الماني

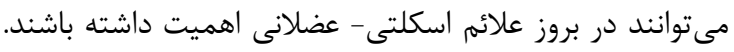
براساس مشاهدات ميدانى نويسند

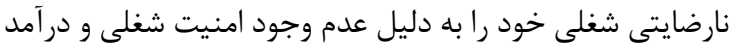

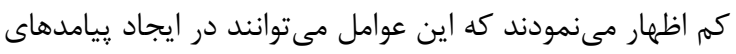

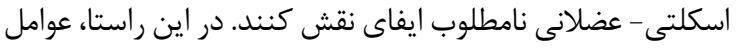

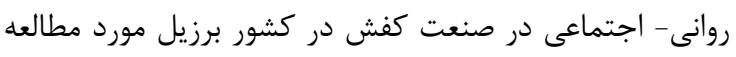

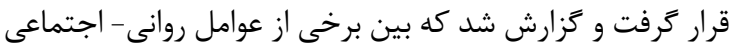

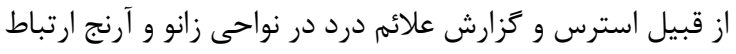

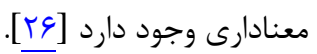

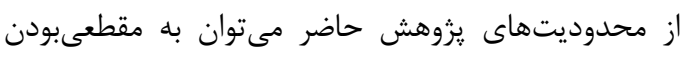

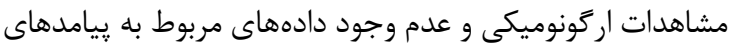

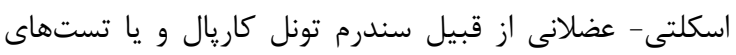

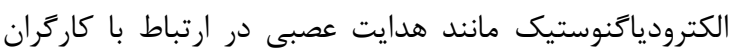

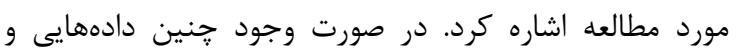
بررسى ارتباط مواجهههاى اركونوميكى تعيينشده با بيامدها،

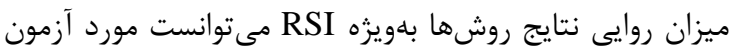

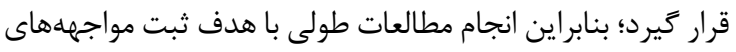

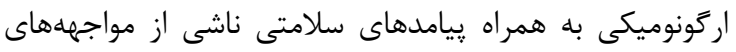

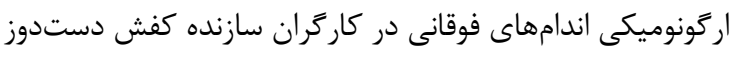

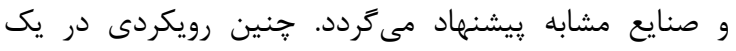

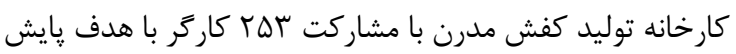

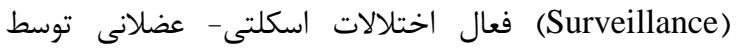
Roquelaure

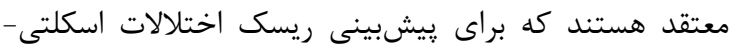

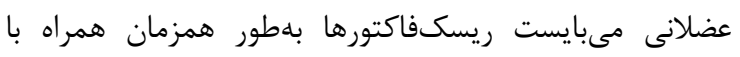

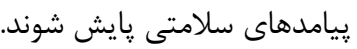

\section{نتيجه تَيرى}

يافتههاى اين مطالعه نشان داد كه كاركران سازنده كفش

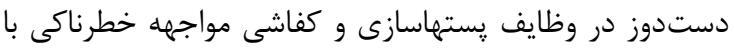
عوامل خطر اختلالات اسكلتى- عضلانى (بهويزه فعاليتهاى

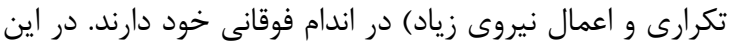

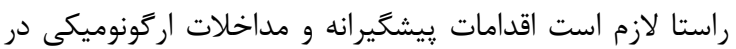
ارتباط با اين دو وظيفه مد نظر قرار كيرند كه در اين زمينه،

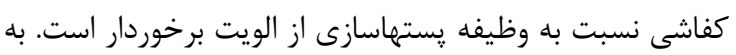

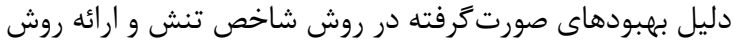

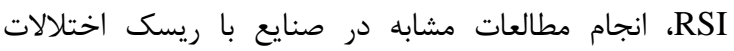
اسكلتى - عضلانى اندام فوقانى توصيه مىشود.

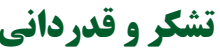

اين مقاله بركرفته از پايان نامه نويسنده اول مقاله مى وباشد كه با حمايت مالى معاونت محترم تحقيقات و فناورى دانشخاه
ريسك مىشود. در كفاشها نيز هر دو عامل تعداد تلاش و شدت

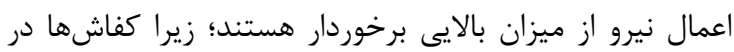

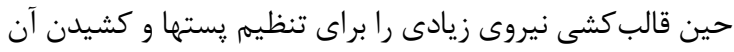

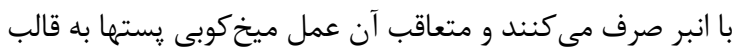

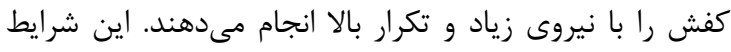

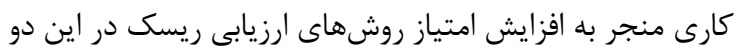
وظيفه مىشود؛ بنابراين براى كاهش آسيبهاى اسكلتى

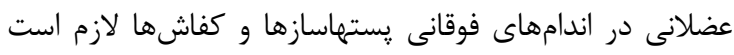

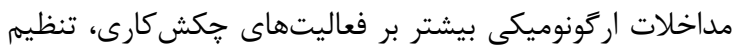

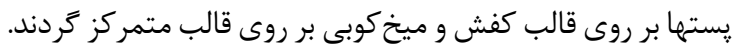

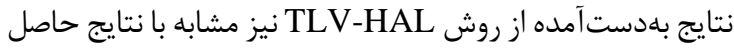

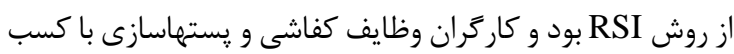

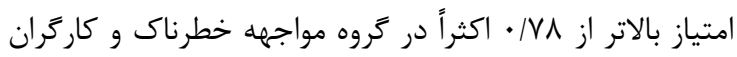

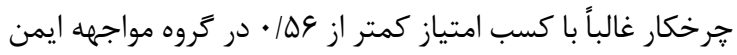
طبقهبندى شدند.

علاوهبراين، براساس نتايج آناليز واريانس يكطرفه مشخص

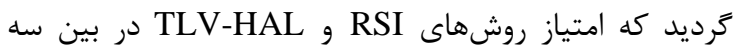
وظيفه بلصورت دو به دو متفاوت است. با توجه به تفاوت معند معنادار

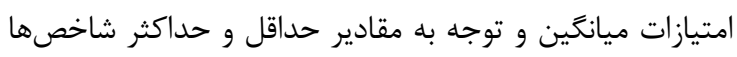

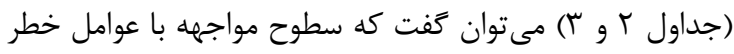

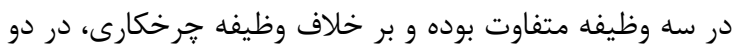

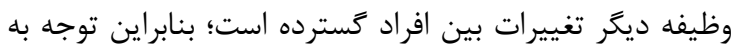

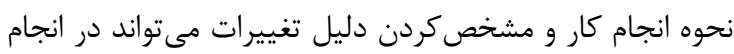

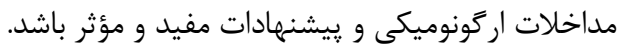

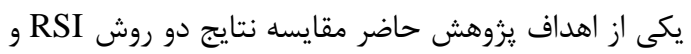

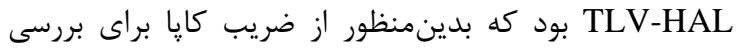

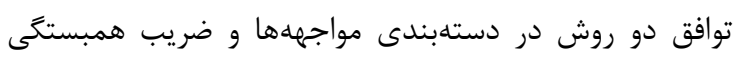
براى بررسى همبستخى نمرات خام افراد استفاده

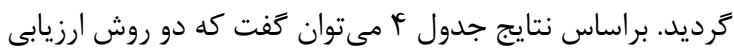

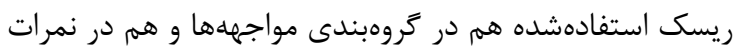

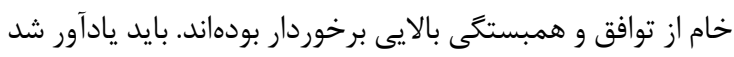

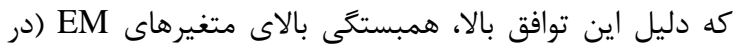

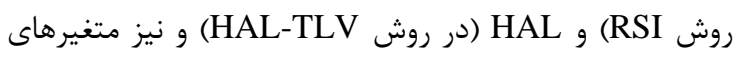

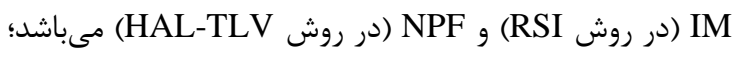

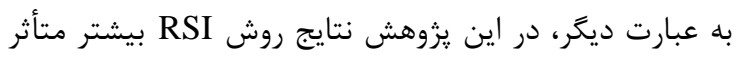

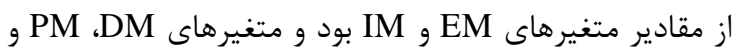

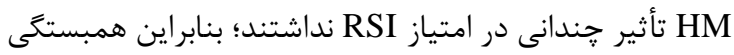

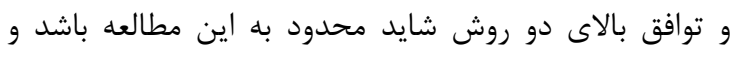

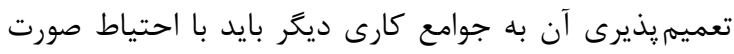

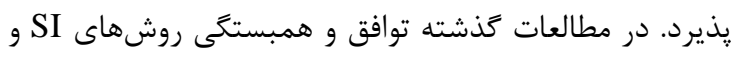

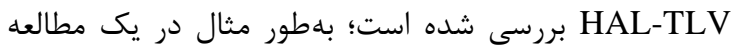

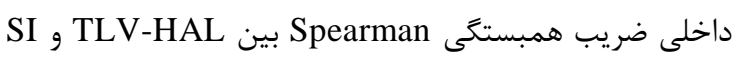

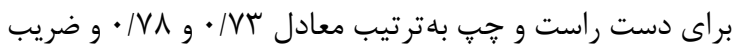

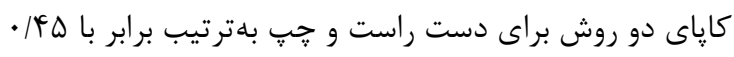


بلوويزه كارگران زحمت كش سازنده كفش دستدوز تشكر و قدردانى مىنمايند.

\section{REFERENCES}

1. Bhattacharya A. Costs of occupational musculoskeletal disorders (MSDs) in the United States. Int J Ind Ergon. 2014;44(3):448-54. DOI: 10.1016/j.ergon.2014.01.008

2. Ohlsson K, Attewell R, Skerfving S. Self-reported symptoms in the neck and upper limbs of female assembly workers: impact of length of employment, work pace, and selection. Scand J Work Environ Health. 1989;15(1):75-80. PMID: 2922592

3. Choobineh A, Lahmi M, Shahnavaz H, Jazani RK, Hosseini M. Musculoskeletal symptoms as related to ergonomic factors in Iranian hand-woven carpet industry and general guidelines for workstation design. Int J Occup Saf Ergon. 2004;10(2):157-68. PMID: 15182472 DOI: 10.1080/ 10803548.2004.11076604

4. Spielholz P, Silverstein B, Morgan M, Checkoway H, Kaufman J. Comparison of self-report, video observation and direct measurement methods for upper extremity musculoskeletal disorder physical risk factors. Ergonomics. 2001;44(6):588-613. PMID: 11373023 DOI: 10.1080/ $\underline{00140130118050}$

5. David GC. Ergonomic methods for assessing exposure to risk factors for work-related musculoskeletal disorders. Occup Med. 2005;55(3):190-9. PMID: 15857898 DOI: 10.1093/ occmed/kqi082

6. Larson BA, Ellexson MT. Blueprint for ergonomics. Work. 2000;15(2):107-12. PMID: 12441496

7. Barondess JA, Cullen MR, de Lateur BJ, Deyo RA, Donaldson KS, Drury CG. Musculoskeletal disorders and the workplace: low back and upper extremities. Washington, DC: National Academy of Sciences; 2001. P. 1-512.

8. Roquelaure Y, Mariel J, Fanello S, Boissiere J, Chiron H, Dano C, et al. Active epidemiological surveillance of musculoskeletal disorders in a shoe factory. Occup Environ Med. 2002;59(7):452-8. PMID: 12107293

9. Vieira ER, Serra MV, de Almeida LB, Villela WV, Scalon JD, Quemelo PR. Symptoms and risks for musculoskeletal disorders among male and female footwear industry workers. Int J Ind Ergon. 2015;48:110-6. DOI: 10.1016/ j.ergon.2015.05.001

10. Seniori Costantini A, Quinn M, Consonni D, Zappa M. Exposure to benzene and risk of leukemia among shoe factory workers. Scand J Work Environ Health. 2003;29(1):51-9. PMID: 12630436

11. Todd L, Puangthongthub ST, Mottus K, Mihlan G, Wing S. Health survey of workers exposed to mixed solvent and ergonomic hazards in footwear and equipment factory workers in Thailand. Ann Occup Hyg. 2008;52(3):195-205. PMID: 18344534 DOI: 10.1093/annhyg/men003

12. Dianat I, Salimi A. Working conditions of Iranian hand-sewn shoe workers and associations with musculoskeletal symptoms. Ergonomics. 2014;57(4):602-11. PMID: 24588329 DOI: $10.1080 / 00140139.2014 .891053$

13. Veisi H, Choobineh A, Ghaem H. Musculoskeletal problems in Iranian hand-woven shoe-sole making operation and developing guidelines for workstation design. Int J Occup Environ Med. 2016;7(2):87-97. PMID: 27112717 DOI: 10.15171/ijoem.2016.725

14. Serratos-Perez JN, Mendiola-Anda C. Musculoskeletal
علوم يزشكى اروميه به انجام رسيده است. بدينوسيله نويسندگان از تمامى افرادى كه در اين مطالعه شركت كردند؛

disorders among male sewing machine operators in shoemaking. Ergonomics. 1993;36(7):793-800. PMID:16219 155 DOI: $10.1080 / 10803548.2005 .11076648$

15. Drinkaus P, Sesek R, Bloswick DS, Mann C, Bernard T. Job level risk assessment using task level ACGIH hand activity level TLV scores: a pilot study. Int J Occup Saf Ergon. 2005;11(3):263-81. PMID: 16219155 DOI: 10.1080/ 10803548.2005.11076648

16. Rosecrance J, Paulsen R, Murgia L. Risk assessment of cheese processing tasks using the Strain Index and OCRA Checklist. Int J Ind Ergon. 2017;61:142-8. DOI: 10.1016/ j.ergon.2017.05.009

17. Bao S, Howard N, Spielholz P, Silverstein B. Quantifying repetitive hand activity for epidemiological research on musculoskeletal disorders--Part II: comparison of different methods of measuring force level and repetitiveness. Ergonomics. 2006;49(4):381-92. PMID: 16690566 DOI: $10.1080 / 00140130600555938$

18. Jones T, Kumar S. Comparison of ergonomic risk assessments in a repetitive high-risk sawmill occupation: Saw-filer. Int $J$ Ind Ergon. 2007;37(9):744-53. DOI: 10.1016/j.ergon.2007.05.005

19. Mohammadian Mastan M, Motamedzade M, Faradmal J. Investigating the Correlations of results of three methods OCRA Index, Strain Index, ACGIH HAL to evaluate the risk of upper extremity musculoskeletal disorders. J Ergon. 2013;1(2):63-71.

20. Moore JS, Garg A. The strain index: a proposed method to analyze jobs for risk of distal upper extremity disorders. Am Ind Hyg Assoc. 1995;56(5):443-58. PMID: 7754975 DOI: 10.1080/15428119591016863

21. Garg A, Moore JS, Kapellusch JM. The Revised Strain Index: an improved upper extremity exposure assessment model. Ergonomics. 2017;60(7):912-22. PMID: 27633493 DOI: 10.1080/00140139.2016.1237678

22. Latko WA, Armstrong TJ, Foulke JA, Herrin GD, Rabourn RA, Ulin SS. Development and evaluation of an observational method for assessing repetition in hand tasks. Am Ind Hyg Assoc J. 1997;58(4):278-85. PMID: 9115085 DOI: $10.1080 / 15428119791012793$

23. Armstrong T. The ACGIH TLV for hand activity level. The occupational ergonomics handbook. Florida: CRC Press; 2006. P. 41-1.

24. Garg A, Kapellusch J, Hegmann K, Wertsch J, Merryweather A, Deckow-Schaefer G, et al. The Strain Index (SI) and Threshold Limit Value (TLV) for Hand Activity Level (HAL): risk of carpal tunnelsyndrome (CTS) in a prospective cohort. Ergonomics. 2012;55(4):396-414. PMID: 22397385 DOI: $10.1080 / 00140139.2011 .644328$

25. Garg A, Kapellusch JM, Hegmann KT, Thiese MS, Merryweather AS, Wang YC, et al. The strain index and TLV for HAL: risk of lateral epicondylitis in a prospective cohort. Am J Ind Med. 2014;57(3):286-302. PMID: 24243166 DOI: 10.1002/ajim.22279

26. Silva JM, Silva LB, Gontijo LA. Relationship between psychosocial factors and musculoskeletal disorders in footwear industry workers. Production. 2017;27:e2013315. DOI: 10.1590/0103-6513.231516 